\title{
CIRCUITO DE PRODUÇÃO DA LARANJA NO BRASIL: DO CULTIVO AOS PRODUTOS INDUSTRIAIS DESTINADOS PRINCIPALMENTE AO MERCADO INTERNACIONAL
}

\author{
Amanda Duarte Mergulhão ${ }^{1}$
}

\begin{abstract}
Resumo: Alguns produtos agropecuários como carnes, soja e café estão entre os principais exportados pelo Brasil. Parte do circuito de produção destes produtos acontece em território brasileiro uma vez que a industrialização normalmente é feita em outros países. O Brasil também tem papel de destaque no comércio mundial de suco de laranja o que estimula este estudo com o objetivo destacar as peculiaridades do circuito de produção da laranja. A maior parte da produção do fruto é destinada a industrialização no estado de São Paulo e o suco vai para venda no mercado internacional. Além disso, as laranjas provêm de produtores comprometidos em direcionar a colheita a grandes grupos industriais específicos que acompanham todas as etapas do cultivo, industrialização e comercialização. As decisões de produção são influenciadas pela variação dos estoques dos sucos, capacidade de processamento da indústria e quantidade de frutos a qual é determinada pelas condições climáticas mundiais.
\end{abstract}

Palavras-chave: circuito de produção; laranja; indústria; agricultura.

\section{CIRCUIT OF ORANGE PRODUCTION IN BRAZIL: FROM CULTIVATION TO INDUSTRIAL PRODUCTS TO SERVE MAINLY THE INTERNATIONAL MARKET}

Abstract: Some farming products such as meat, soy and coffee are among the main exported by Brazil. Part of the circuit of production of these products happens in Brazil while the industrialization is usually made in other countries. Brazil also has a prominent role in the world trade of orange juice what inspires this study which aims to highlight the peculiarities of the spatial circuit of orange production. Most of the production of the fruit is directed to industrialization in the state of São Paulo and the juice goes for sale in the international market. Besides that, the oranges come from producers committed to direct the fruits to large specific industrial groups which follow all stages of cultivation, industrialization and commercialization. Production decisions are influenced by the variation of juice stocks, processing capacity of the industry, amount of fruits which is determined by the global weather conditions.

Keywords: circuit of production; orange; industry; agriculture

\footnotetext{
${ }^{1}$ Instituto Brasileiro de Geografia e Estatística (IBGE). amandam0302@outlook.com. Estudos Geográficos, Rio Claro, 16(2): 141-155, jul./dez. $2018 \quad$ (ISSN 1678-698X) http://www.periodicos.rc.biblioteca.unesp.br/index.php/estgeo
} 


\section{INTRODUÇÃO}

Dentre as culturas de lavoura permanente, a produção comercial de laranja se destaca no Brasil pelas peculiaridades das relações que se estabelecem entre agricultores e compradores industriais, bem como entre trabalhadores e proprietários do capital desde o surgimento de sua produção comercial nos anos 1960. Normalmente, a produção é proveniente de produtores comprometidos em direcionar a produção a grandes grupos industriais específicos que acompanham todas as etapas do cultivo e vendem a produção final do suco de laranja respeitando contratos de comercialização estabelecidos entre residentes de diversos continentes, destaque para América do Norte e Europa, o que confere a participação de distintos agentes neste circuito de produção. Portanto, trata-se de um circuito realizado predominantemente em território nacional, mas a negociação do produto já industrializado e a formação de preços da laranja in natura ocorrem predominantemente no mercado internacional. O recorte territorial da produção e da industrialização são bastante concentrados no estado de São Paulo.

Acompanhar o surgimento e evoluir dessas relações é a marca da primeira parte do estudo que é aprimorada nos itens seguintes com a análise dos dados e mudanças mais recentes no complexo citricultor brasileiro. Primeiramente, explorase a concentração territorial da produção agrícola e sua periodicidade anual. As relações entre cultivadores e produtores industriais são descritas no momento seguinte explorando volume de produção, rendimentos industriais, formação de preços e custos ao longo do tempo culminando na formação dos grandes grupos industriais.

O objetivo é mostrar que os grandes grupos industriais se tornam cada vez menores numericamente, mas com alcances significativos no comércio mundial, expansivos na Europa na última década. A integração com o setor agrícola é cada vez mais amplo, determinado também pelos acordos de comercialização internacional.

Em suma, o trabalho registra as relações que se formam e se mantém para dar continuidade ao complexo citricultor brasileiro. Sob este ponto de vista, este estudo vem complementar a análise das categorias e atores sociais feita por Cássio Arruda Boechat (2015). Segundo o autor, é consenso entre grande parte dos pesquisadores que todos os elos da cadeia produtiva do complexo agroindustrial citrícola apresentam dificuldades para se manter desde os anos 2000. Os principais problemas são de origem endógena (centralização do capital com a indústria, integração vertical presente nos pomares próprios das indústrias e no sistema de logística de transporte, alto custo dos insumos agrícolas) e exógena (protecionismo dos principais compradores internacionais, centralização do capital por parte das cadeias de supermercados, incidência de pragas nas lavouras, variação de preços de laranja na bolsa de Nova lorque). Ainda assim, o suco de laranja é um item de destaque na pauta exportadora brasileira devido a sua participação no mercado internacional deste produto. Os subprodutos óleos, essências e farelos utilizados nas rações animais são formados utilizando pouco mais de $50 \%$ das laranjas colhidas e seguem abastecendo predominantemente os mercados nacionais.

Estudos Geográficos, Rio $\quad$ Claro, $\quad$ 16(2): $\quad 141-155, \quad$ jul./dez. $2018 \quad$ (ISSN 1678 -698X) http://www.periodicos.rc.biblioteca.unesp.br/index.php/estgeo 


\section{A FORMAÇÃO DE FLUXOS INTER E INTRA-REGIONAIS NO CONTEXTO DA EXPANSÃO DO MEIO TÉCNICO- CIENTÍFICO INFORMACIONAL}

A maior parte da produção de laranja provém do estado de São Paulo nos meses de setembro e outubro. As colheitas anuais iniciaram no final dos anos 1960 sendo grande parte destinada à fabricação de sucos para exportação como fazia a Citrosuco, empresa criada em 1963 por Carl Fischer e conhecida por ser a primeira fábrica processadora de suco concentrado de laranja e subprodutos na cidade de Matão, interior de São Paulo. Matão e as demais regiões produtoras de laranja foram agraciadas pelo dinamismo econômico proveniente da cafeicultura paulista, principalmente no que diz respeito ao acúmulo de recursos técnicos e financeiros que foram capazes de mudar a base técnica e organizacional do circuito de produção e com isso chegar à revolução técnica-científica e suas novas formas de produção material e não material.

A terra, o trabalho e o capital sempre foram os principais fatores de produção e permanecem no período técnico-científico, o que muda é a reorganização da relação entre estes três fatores. Ademais, a incorporação da ciência, da tecnologia e da informação aumentam a quantidade e a qualidade da produção agrícola gerando profundas transformações econômicas e socioespaciais (SAMPAIO, 2003).

No estado de São Paulo esta evolução acabou por criar as condições técnicas e econômicas para uma organização de atividades agrícolas integradas à indústria inclusive estimulando produção de insumos para a agricultura bem como máquinas e equipamentos para ambos os setores. Segundo Sampaio (2003), as crescentes substituições dos insumos naturais pelos artificiais produzidos em escala industrial e a produção de subsistência pela economia de mercado estimulam a inter-relação entre agricultura e outros setores econômicos.

A consequência foi importante volume de produção industrial associado à atividade agropecuária integrando capitais controlados por empresas nacionais de grande porte e multinacionais. Conforme identificaram Santos \& Silveira (2006), a indústria acaba por normatizar a produção agrícola, determinar os fluxos e apontar os preços no mercado nacional e internacional.

O crescimento e especialização da produção estimularam fluxos inter e intra regionais no território brasileiro durante a década de 1970. A comercialização permitiu intensificar as relações entre cidade de São Paulo e porto de Santos (ELIAS, 1996).

Na década de 1980, o Brasil supera a produção norte-americana e se torna - maior produtor mundial de laranja o que foi possível graças à união de uma citricultura desenvolvida e uma indústria competitiva concomitantemente a um período de queda na produção da Flórida. Nessa fase, os preços do suco e da fruta atingiram valores recordes, fazendo com que a citricultura brasileira avançasse a cada safra. Foi um período marcado pelo ritmo acelerado de implantação de novos pomares em São Paulo, com taxas de expansão da área cultivada com citros de $12 \%$ a $18 \%$ ao ano, e pela entrada de muitos produtores (NEVES, 2010).

A produção de laranja em grande escala no Paraná tem inicio no final da década de 1980 com o objetivo de reduzir as compras provenientes de São Paulo. Nos demais estados produtores, o cultivo mais expressivo da laranja é mais recente,

Estudos Geográficos, Rio Claro, 16(2): 141-155, jul./dez. $2018 \quad$ (ISSN 1678-698X) http://www.periodicos.rc.biblioteca.unesp.br/index.php/estgeo 
sendo variável o período de intensificação da colheita destacando-se os meses de junho e julho (Tabela 1).

Tabela 1-Distribuição do valor da produção de laranja segundo mês da colheita e principais Unidades da Federação produtoras de acordo com o Censo Agropecuário de 2006

\begin{tabular}{|c|c|c|c|c|}
\hline Produto & Sergipe & Bahia & São Paulo & Paraná \\
\hline Laranja_Janeiro & $5,8 \%$ & $3,5 \%$ & $0,6 \%$ & $0,6 \%$ \\
\hline Laranja_Fevereiro & $0,4 \%$ & $1,4 \%$ & $1,4 \%$ & $0,3 \%$ \\
\hline Laranja_Março & $3,8 \%$ & $1,6 \%$ & $1,7 \%$ & $0,4 \%$ \\
\hline Laranja_Abril & $3,9 \%$ & $1,3 \%$ & $0,6 \%$ & $0,2 \%$ \\
\hline Laranja_Maio & $2,3 \%$ & $4,4 \%$ & $2,3 \%$ & $3,7 \%$ \\
\hline Laranja_Junho & $33,2 \%$ & $50,2 \%$ & $8,0 \%$ & $9,3 \%$ \\
\hline Laranja_Julho & $16,6 \%$ & $15,7 \%$ & $14,5 \%$ & $22,4 \%$ \\
\hline Laranja_Agosto & $5,6 \%$ & $3,7 \%$ & $16,7 \%$ & $14,8 \%$ \\
\hline Laranja_Setembro & $5,5 \%$ & $5,6 \%$ & $18,0 \%$ & $43,1 \%$ \\
\hline Laranja_Outubro & $1,6 \%$ & $2,0 \%$ & $24,4 \%$ & $2,2 \%$ \\
\hline Laranja_Novembro & $17,0 \%$ & $7,2 \%$ & $8,9 \%$ & $1,1 \%$ \\
\hline \multirow[t]{2}{*}{ Laranja_Dezembro } & \begin{tabular}{|l|}
$4,5 \%$ \\
\end{tabular} & $3,5 \%$ & $2,9 \%$ & $2,0 \%$ \\
\hline & \multicolumn{4}{|c|}{ \% da UF em relação à produção nacional } \\
\hline Laranja & $4 \%$ & $8 \%$ & $70 \%$ & $4 \%$ \\
\hline
\end{tabular}

Fonte: IBGE/CensoAgro 2006

Esta disposição geográfica de cultivo de laranja no Brasil não tem grandes variações sendo o estímulo para plantar influenciado pelo mercado internacional que, por sua vez, oscila conforme as condições climáticas ou possíveis pragas que atacam os laranjais, basicamente da Flórida e/ou de São Paulo, e preços de outras culturas como a soja que têm desestimulado a produção de laranja em favor do cultivo deste grão. No estado que mais produz laranja no Brasil predominam os pequenos proprietários, aproximadamente $87 \%$ do total segundo Lidiane Maciel (2012) que em sua maioria estabelecem contratos de vendas dos frutos a grandes grupos econômicos da região.

Parte das indústrias citrícolas está fisicamente próxima das plantações. Porém, as empresas agroindustriais de grande porte estão inseridas em círculos de cooperação fisicamente distantes, tanto para venda do produto final como para compra de insumos e matéria-prima. Por isso, são capazes de criar relações sobre o território transformando radicalmente as tradicionais relações entre cidade e campo. Estes dois espaços passam a emitir e receber uma grande quantidade de fluxos de matéria e de informação (ELIAS, 1996).

Trata-se da relação entre cidade e campo visualizada por Milton Santos [1988](2008) que abrange não só áreas limítrofes, mas cidades que mantém relações intensas com outras mais distantes. Como consequência, tem-se a expansão do meio técnico-científico-informacional e total reorganização do território urbano e rural. Sampaio (2003) concorda e complementa a análise esclarecendo que antes da revolução tecnológica os circuitos de produção se esgotavam no interior do próprio estabelecimento agrícola. Hoje, estes circuitos são somados aos circuitos de cooperação e extrapolam os limites da propriedade rural.

É justamente a adição de produtos químicos, a utilização da biotecnologia, o uso intensivo de máquinas agrícolas que contribuem para alterar a composição Estudos Geográficos, Rio Claro, 16(2): 141-155, jul./dez. $2018 \quad$ (ISSN 1678 -698X) http://www.periodicos.rc.biblioteca.unesp.br/index.php/estgeo 
técnica e orgânica da terra, o que amplia o meio técnico-científico-informacional no ambiente rural e ajuda a explicar a interiorização da urbanização. A unificação entre urbano e rural se dá por vias econômicas, mediante a substituição da economia natural por atividades agrícolas integradas à indústria, pela intensificação da divisão do trabalho e das trocas intersetoriais, pelo movimento do capital industrial e financeiro (ELIAS, 1996).

Neste contexto, esmiuçar as relações geradas no circuito de produção da laranja é imprescindível para entender estes fenômenos.

\section{DO CULTIVO DE LARANJA ATÉ A COLHEITA: UMA PARCERIA ENTRE PRODUTORES E POUCAS GRANDES EMPRESAS INDUSTRIAIS}

Os pequenos e médios produtores normalmente vendem sua colheita a indústrias específicas de grande porte, portanto o circuito de produção da laranja é caracterizado por agentes de diferentes tamanhos, uma particularidade que se identifica com os estudos de Arroyo (2008). Segundo Boechat (2015), a citricultura é uma atividade na qual a produção se destina basicamente ao suprimento da fruta para a indústria processadora. As relações de trabalho seguem características particulares, os pequenos produtores ainda respondem pela maior parte da produção, mas estão perdendo espaço para produtores de médio porte, sendo que ambos vendem grande parte da produção de laranja direto para indústria. A produção restante utilizada no beneficiamento, de $30 \%$ a $50 \%$, provém de pomares próprios das indústrias.

A parceria se estende para todas as etapas do cultivo. A Citrosuco, por exemplo, possui banco próprio de germoplasma de sementes que são cuidadosamente cultivadas por aproximadamente quatro meses até se tornarem pequenas mudas, quando já estão prontas para serem entregue aos produtores. As mudas demoram 3 anos após o plantio em local definitivo para começar a produção considerada lucrativa. Dependendo das características e das condições de solo e clima, as variedades cítricas apresentam ciclo de desenvolvimento variando de 10 a 16 meses entre o florescimento e a maturação dos frutos. Um pomar dura aproximadamente 20 anos. Em geral, 50 t/ha é a produtividade ideal para um pomar. A produtividade de cada pé depende do tipo da laranja, a Hamlim é considerada a variedade mais produtiva chegando a $300 \mathrm{~kg}$ ou $400 \mathrm{~kg}$ por planta (de 8 a 10 caixas de $40 \mathrm{~kg} /$ pé/ano).

De acordo com publicação do Instituto Observatório Social, os produtores pagam um valor fixo para os trabalhadores do laranjal em São Paulo, aproximadamente um salário mínimo paulista de $R \$ 690,00$ mais um montante correspondente à produtividade, isto é, mais $R \$ 0,42$ por caixa adicional a produção de 50 caixas de laranja por dia no ano de 2012. A maior parte da mão de obra ocupada no circuito produtivo da laranja em São Paulo é temporária, aproximadamente $78 \%$, sendo apenas $22 \%$ mão de obra permanente que inclui proprietários, arrendatários, parceiros, administradores, tratoristas e mensalistas.

Segundo pesquisa CEPEA/Esalq, o produtor tinha que vender à indústria 22 caixas de laranja para ter um salário mínimo em 2001. A relação subiu para 47 caixas dez anos depois. Para os produtores, o custo com a mão de obra segue como principal item de despesa com os pomares, aproximadamente $22 \%$ na safra $2011 / 2012$.

Estudos Geográficos, Rio $\quad$ Claro, $\quad$ 16(2): $\quad 141-155, \quad$ jul./dez. $2018 \quad$ (ISSN 1678 -698X) http://www.periodicos.rc.biblioteca.unesp.br/index.php/estgeo 
Os preços pagos aos produtores oscilam de acordo com o preço do fruto, que por sua vez são determinados de acordo com quantidade produzida, área plantada, alterações na produtividade em território brasileiro, estoque mundial de sucos de laranja, mudanças no padrão de consumo mundial ou oscilações nos preços internacionais do fruto. Na safra 2008/2009 tanto o volume como os preços médios do suco de laranja cotados na Bolsa de Valores de Nova lorque tiveram seus valores bem reduzidos em relação ao ano safra anterior. O Centro de Estudos Avançados de Economia Aplicada (CEPEA) estimou um custo operacional médio de $\mathrm{R} \$ 10,36$ com preços médios de $U \$ \$ 5,07$ por cada caixa de 40,8 $\mathrm{kg}$ de laranja em 2009. Assumindo a cotação média de $R \$ 2,3$ para cada dólar, o preço médio de $\mathrm{R} \$ 11,66$ mostra que muitos produtores estavam trabalhando com prejuízo (BOECHAT, 2015).

A queda na produção ajudou a acentuar os preços, de 2009 para 2010, subiu de $R \$ 6$ para $R \$ 15$. Em 2010, a queda na produção de laranja da Flórida (EUA) provocou elevação dos preços internacionais até princípios de 2011 . O consumo internacional em queda e a abundância da oferta provocaram redução no preço pago ao produtor em cerca de $50 \%$ no final de 2011 fazendo com que o preço pago aos produtores pela caixa de laranja atingisse o valor mínimo de $R \$ 10,00$, insuficientes para suprir os custos que atingiram $R \$ 16,00$ por caixa segundo a Associação Brasileira dos Citricultores (ASSOCITRUS). A superprodução brasileira, que iniciou em 2010 teve pico em 2011 e ainda se manteve alta em 2012 fez com que muitos produtores deixassem os frutos apodrecerem nos pés (Tabela 2).

\begin{tabular}{|c|c|c|c|c|c|c|c|c|c|}
\hline Variável & 2008 & 2009 & 2010 & 2011 & 2012 & 2013 & 2014 & 20 & 2011 \\
\hline $\begin{array}{l}\text { Área destinada à colheita de } \\
\text { laranja (Hectares) }\end{array}$ & 837.031 & 802.528 & 851.142 & 818.685 & 762.765 & 719.360 & 689.103 & 681.816 & 669.195 \\
\hline $\begin{array}{l}\text { Valor da produção de laranja (Mil } \\
\text { Reais) }\end{array}$ & 5.100 .062 & 4.695 .049 & 6.151 .544 & 6.555 .645 & 4.595 .830 & 4.765 .624 & 5.535 .749 & 5.692 .147 & 8.380 .099 \\
\hline $\begin{array}{l}\text { Quantidade produzida de laranja } \\
\text { (Toneladas) }\end{array}$ & 18.538 .084 & 17.618 .450 & 18.503 .139 & 19.811 .064 & 18.012 .560 & 17.549 .536 & 16.928 .457 & 16.939 .560 & 17.251 .291 \\
\hline $\begin{array}{l}\text { Sergipe } \\
\text { Bahia }\end{array}$ & \begin{tabular}{r|}
772.070 \\
1.116 .896 \\
\end{tabular} & \begin{tabular}{|l|}
784.382 \\
906.965 \\
\end{tabular} & \begin{tabular}{|l|}
805.962 \\
987.813 \\
\end{tabular} & \begin{tabular}{r|}
822.468 \\
1.030 .763
\end{tabular} & \begin{tabular}{r|}
821.940 \\
1.036 .841
\end{tabular} & $\begin{array}{l}626.440 \\
994.817 \\
\end{array}$ & \begin{tabular}{r|}
614.227 \\
1.026 .167
\end{tabular} & \begin{tabular}{r|}
552.817 \\
1.161 .187
\end{tabular} & $\begin{array}{r}489.156 \\
1.129 .785\end{array}$ \\
\hline Minas Gerais & $\begin{array}{r}1.110 .8960 \\
583.924 \\
\end{array}$ & \begin{tabular}{|l|}
006.965 \\
749.987 \\
\end{tabular} & $\begin{array}{r}91 . .813 \\
816.875 \\
\end{array}$ & $\begin{array}{r}1.030 .163 \\
824.041 \\
\end{array}$ & $\begin{array}{r}1.036 .841 \\
864.213 \\
\end{array}$ & $\begin{array}{l}999.817 \\
894.543 \\
\end{array}$ & $\begin{array}{l}7.026 .167 \\
940.444 \\
\end{array}$ & $\begin{array}{l}1.161 .187 \\
987.363 \\
\end{array}$ & $\begin{array}{l}1.129 .185 \\
961.223 \\
\end{array}$ \\
\hline São Paulo & 14.537 .610 & \begin{tabular}{|l|l|}
13.642 .165 \\
\end{tabular} & $\begin{array}{l}14.269 .383 \\
\end{array}$ & 15.293 .506 & \begin{tabular}{|l|l|}
13.365 .983 \\
\end{tabular} & \begin{tabular}{|l|l|}
13.018 .878 \\
\end{tabular} & 12.290 .567 & $\begin{array}{l}12.279 .253 \\
\end{array}$ & 12.847 .146 \\
\hline Paraná & 517.400 & 520.000 & 587.740 & 784.543 & 913.214 & 976.503 & 979.682 & 903.195 & 741.381 \\
\hline Rio Grande do Sul & 335.266 & 350.650 & 369.435 & 391.692 & 362.073 & 390.538 & 379.460 & 351.499 & 395.623 \\
\hline Outros & 674.918 & 664.301 & 665.931 & 664.051 & 648.296 & $\begin{array}{l}647.817 \\
\end{array}$ & 697.910 & $\begin{array}{l}04.246 \\
\end{array}$ & 686.977 \\
\hline & Safra 2008/2009 & Safra 2009/2010 & Safra 2010/2011 & Safra 2011/2012 & Safra 2012/2013 & Safra 2013/2014 & Safra 2014/2015 & Safra 2015/2016 & Safra 2016/2017 \\
\hline $\begin{array}{l}\text { Quantidade produzida de laranja } \\
\text { (Milhöes Caixas)* }\end{array}$ & 314 & 304 & 268 & 416 & 387 & 290 & 309 & 301 & 245 \\
\hline $\begin{array}{l}\text { Estoques mundiais de suco de } \\
\text { laranja brasileiro nas passagens } \\
\text { de safras (30/junho) }\end{array}$ & 440 & 249 & 214 & 662 & 766 & 535 & 510 & 352 & $x$ \\
\hline \multirow[t]{2}{*}{$\begin{array}{l}\text { Estoques no Brasil de suco de } \\
\text { laranja nas passagens de safras } \\
(30 / j u n h o)^{* \star}\end{array}$} & & & 71 & 462 & 551 & 337 & 336 & 162 & $\mathrm{x}$ \\
\hline & 2008 & 2009 & 2010 & 2011 & 2012 & 2013 & 2014 & 2015 & 2016 \\
\hline $\begin{array}{l}1033.2022 \text { Refrescos, sucos ou } \\
\text { néctares de laranja, prontos para } \\
\text { consumo (Produção em } 1000 \\
\text { litros) }\end{array}$ & 51.263 & 82.766 & 83.628 & 74.282 & 126.322 & 185.005 & 341.702 & 890.343 & $\mathrm{x}$ \\
\hline $\begin{array}{l}1033.2050 \text { Sucos concentrados } \\
\text { de laranja (Produção em } 1000 \\
\text { litros) }\end{array}$ & 1.003 .178 & 1.025.964 & 1.002 .680 & 1.708 .526 & 1.526 .247 & 1.117 .370 & 1.165 .208 & 1.007.139 & $\mathrm{x}$ \\
\hline $\begin{array}{l}1033.2022 \text { Refrescos, sucos ou } \\
\text { néctares de laranja, prontos para } \\
\text { consumo (Valor da Produção em } \\
1000 \text { Reais) }\end{array}$ & 101.973 & 102.498 & 109.741 & 65.853 & 125.258 & 202.659 & 212.725 & 354.216 & $\mathrm{x}$ \\
\hline $\begin{array}{l}1033.2050 \text { Sucos concentrados } \\
\text { de laranja (Valor da Produção em } \\
1000 \text { Reais) }\end{array}$ & 3.557 .621 & 3.451 .652 & 3.648 .055 & 6.353 .990 & 6.212 .518 & 5.232 .941 & 5.808 .561 & 6.496 .644 & $x$ \\
\hline $\begin{array}{l}\text { Consumo brasileiro de suco de } \\
\text { larania** }\end{array}$ & 33 & 36 & 39 & 42 & 48 & 53 & 62 & 63 & 69 \\
\hline $\begin{array}{l}\text { Estimativa de caixas que foram } \\
\text { processadas para atender a } \\
\text { demanda brasileira por ano } \\
\end{array}$ & 8,4 & 9,5 & 9,4 & 11,1 & 12,6 & 15,0 & 14,9 & 19,0 & 19,8 \\
\hline \multirow{2}{*}{$\begin{array}{l}\begin{array}{l}\text { Rendimento industrial de suco na } \\
\text { frutata*** }\end{array} \\
\end{array}$} & 252,88 & 262,52 & 240,58 & 265,36 & 263,54 & 282,00 & 240,50 & 302,50 & 286,37 \\
\hline & \begin{tabular}{l|} 
Safra 2008/2009 \\
\end{tabular} & \begin{tabular}{l|} 
Safra $2009 / 2010$ \\
\end{tabular} & \begin{tabular}{l|l} 
Safra 2010/2011 \\
\end{tabular} & \begin{tabular}{l|} 
Safra 2011/2012 \\
\end{tabular} & \begin{tabular}{l|} 
Safra 2012/2013 \\
\end{tabular} & \begin{tabular}{l|} 
Safra 2013/2014 \\
\end{tabular} & \begin{tabular}{|l|} 
Safra 2014/2015 \\
\end{tabular} & \begin{tabular}{|l|} 
Safra 2015/2016 \\
\end{tabular} & Safra 2016/2017 \\
\hline $\begin{array}{l}\text { Produção de suco de laranja das } \\
\text { indústrias paulistas }{ }^{* * *}\end{array}$ & 1.129 & 1.016 & 1.025 & 1.519 & 1.192 & 851 & 1.128 & 865 & 684 \\
\hline 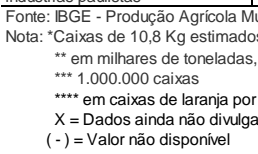 & $\begin{array}{l}\text { Unicipal e Pesaquisa } \\
\text { s pela Fundecitro } \\
\text { FCOJ equiv } 66 \text { Brix. } \\
\text { tonelada de FCOJ e } \\
\text { dos }\end{array}$ & idustrial Anual Prod & uto / Fundecitro & & & & & & \\
\hline
\end{tabular}

Estudos Geográficos, Rio $\quad$ Claro, $\quad$ 16(2): $\quad 141-155, \quad$ jul./dez. $2018 \quad$ (ISSN $\quad$ 1678-698X) http://www.periodicos.rc.biblioteca.unesp.br/index.php/estgeo 
Diferente do Instituto Brasileiro de Geografia e Estatística (IBGE), a Associação Nacional dos Exportadores de Sucos Cítricos (CitrusBR) estimou produção de 428 milhões de caixas de laranja em 2011, o que é significativamente superior à capacidade de processamento da indústria de aproximadamente 247 milhões de caixas por ano. Dados da Fundecitro também apontam aumento da produção com estimativas por ano-safra. Em comum, há excesso de produção em 2011 e no ano seguinte, quando volta-se a produzir uma safra acima do esperado, cerca de 365 milhões de caixas segundo a CitrusBR. Neste mesmo ano, os EUA proibiram a importação do suco concentrado de laranja brasileiro devido ao uso do fungicida carbendazim nas lavouras. Com o consumo em queda em países tradicionalmente consumidores, a exemplo da Alemanha e do Japão, o excedente de produção chegou a 80 milhões de caixas de 40,8 quilos de laranja. Segundo o Relatório do Departamento de Agricultura dos Estados Unidos (USDA), o volume de processamento da indústria cítrica foi de 10,91 milhões de toneladas no período (aproximadamente 267 milhões de caixas) e o consumo in natura 5,45 milhões de toneladas (aproximadamente 133,5 milhões de caixas). Já no início de 2012, a unidade da Citrosuco em Matão (SP) parou de processar sucos diante do excesso de frutos e da inviabilidade de fazer estoques.

Houve prorrogação da linha de financiamento para estocagem da laranja e, com isso, a indústria adquiriu 40 milhões de caixas a mais que o previsto no início da safra, o que ajudou a amenizar os prejuízos dos agricultores segundo Christian Lohbauer, presidente executivo da CitrusBR. A tendência era de aumento do custo de produção diante da necessidade do uso de fungicidas com ingredientes ativos mais caros. Apesar do aumento das despesas com defensivos, a mão de obra continuou sendo o principal item dos custos, em torno de $22 \%$ das despesas dos pomares da safra paulista de $2011 / 2012$. Pelo menos $60 \%$ dos custos intermediários são adubos e fertilizantes, 10\% embalagens, 7\% combustíveis, 3\% transporte e movimentação de cargas e quase $20 \%$ são os serviços financeiros envolvidos para impulsionar o cultivo dos pomares, além dos serviços auxiliares e de organização empresarial e patronal.

Dados do Instituto de Economia Agrícola (IEA) apontaram redução de 52,3 mil hectares de área de laranjais plantados entre 2012 e 2014. O relatório da Coordenadoria de Defesa Agropecuária do Estado de São Paulo mostra que 26\% da área que antes era destinada a plantação de laranja pertencem agora à produção de grãos como soja e milho, isto porque estas culturas vêm proporcionando lucros maiores, justamente por causa dos custos da produção dos laranjais, da dificuldade para comercializar a safra e das pragas que vêm prejudicando as lavouras. Ademais, os produtores brasileiros receberam em torno de US\$4 a caixa em 2014 enquanto os produtores da Flórida receberam US $\$ 14$ segundo o presidente da ASSOCITRUS.

Simultaneamente a redução dos hectares há o desenvolvimento de novas plantas. Até 2012 não era permitido desenvolver procedimentos artificiais que envolvessem o florescimento e a frutificação das laranjeiras no Brasil, restrição abolida com a plantação de 650 mudas de laranjeiras com alterações genéticas em 2013. Trata-se dos primeiros exemplares transgênicos para evitar duas das principais doenças que invadem as plantações segundo Antônio Juliano Ayres que participa destes estudos do Fundo de Defesa da Citricultura (FUNDECITRUS).

A diversificação das variedades nos pomares citrícolas é importante porque estratifica a colheita de laranja ao longo do ano e assim evita a concentração da oferta em alguns meses. Isto também permite ao citricultor vender em épocas de Estudos Geográficos, Rio Claro, 16(2): 141-155, jul./dez. 2018 (ISSN 1678-698X) http://www.periodicos.rc.biblioteca.unesp.br/index.php/estgeo 
preços mais elevados e possibilita à indústria o prolongamento do período de processamento de laranjas para produção de suco. Atualmente, os pomares do estado de São Paulo apresentam 55\% das árvores das variedades tardias (Natal e Valência), 23\% com variedades precoces (Hamilin, Westin, Rubi e Pineapple) e 22\% com variedade meia-estação, como a laranja-pera no Rio de Janeiro. A preferência dos citricultores é pelas variedades tardias, em função da sua maior produtividade (NEVES, 2010).

Considerando todos os tipos de laranja, há redução de 2,9 milhões de plantas cítricas no estado de São Paulo no primeiro semestre de 2016 segundo dados da Secretaria de Agricultura e Abastecimento do estado de São Paulo. De acordo com os produtores, 2 milhões por conta de pragas e 1,5 por mudança de atividade. Em conjunto com a redução das áreas plantadas há redução no número de empresas processadoras dos frutos. No caso dos produtores passa a ter importância crescente os produtores de médio porte, no âmbito da indústria consolidam-se os grandes complexos industriais.

\section{AVANÇOS NA CONCENTRAÇÃO DA ÁREA PLANTADA E CONSOLIDAÇÃO DE GRANDES GRUPOS INDUSTRIAIS}

A participação crescente do Brasil na produção e exportação de suco concentrado de laranja aconteceu sob o comando de grandes grupos, principalmente Cutrale, Citrosuco, Cargill e Frutesp nos anos 1990. Considerando as extratoras, essas quatro empresas concentravam pouco mais de $80 \%$ da capacidade instalada na produção de suco de laranja brasileiro em 1994. A Frutesp foi comprada pelo grupo francês Dreyfus e seu nome passou a ser Coinbra/Frutesp nos anos 2000 (SANTOS, \& SILVEIRA, 2006).

Cutrale, Citrosuco, Cargill fazem o transporte da plantação para a indústria com frota própria de caminhões tanques que são térmicos. Ao chegar aos terminais do porto, o suco é armazenado em tanques frigoríficos até a autorização para embarque nos navios. A movimentação do produto até os navios tanques é feita por tubos interligados entre os terminais e o cais, os sucodutos. Chegando aos navios, o suco é armazenado em tanques especiais, tank farm, onde é mantido em baixas temperaturas.

A Cutrale é uma das três empresas com operações no Brasil que controla cerca de $80 \%$ do mercado mundial de suco de laranja, possui uma fábrica de sucos em Portugal e outra muito importante na Flórida. A empresa foi fundada em 1967 em Araraquara (SP), mantendo lá sua principal fonte de atividade e um setor de Packing House (setor de embalagens) local onde as frutas são embaladas em caixas de papelão ou em sacolas tramadas e depois acondicionadas em pallets para facilitar o transporte e evitar disseminação de pragas e doenças.

A Cutrale tem atualmente mais fábricas paulistas nos municípios de Colina, Conchal, Uchôa, Itápolis. A maior parte da produção é transformada em suco de laranja, sendo que $98 \%$ da produção são destinadas à exportação para mais de 90 países. Por meio do processo de extração e concentração, parcela da produção do suco de laranja é concentrada e congelada, a princípio sem perda de suas qualidades e sem uso de aditivos, sendo, após este processo, congelada a baixas temperaturas para preservar suas propriedades naturais, principalmente quanto à vitamina C. O objetivo é conservar sabor e qualidade originais do suco quando ele for reconstituído.

Estudos Geográficos, Rio Claro, 16(2): 141-155, jul./dez. $2018 \quad$ (ISSN 1678-698X) http://www.periodicos.rc.biblioteca.unesp.br/index.php/estgeo 
Além da fruta "in natura" e do suco de laranja, a Cutrale comercializa o farelo de polpa cítrica a partir de cascas, sementes e polpas de laranjas, um composto que equivale a aproximadamente $50 \%$ do peso de cada fruta que é acondicionado em pallets após ressecamento e trituração para ser utilizado como insumo na ração de rebanhos bovinos (leite e corte). É aconselhável que o uso se restrinja ao máximo de $30 \%$ da matéria seca para cada animal adulto. A empresa também extrai óleos essenciais, a partir de substancias que são liberadas pelas cascas do fruto durante 0 processo de corte para extração do suco.

A Citrosuco foi fundada em 1963 em Matão (SP). A fábrica de Limeira (SP) é fundada treze anos depois. Em 1992, o Grupo Fischer assumiu o controle da Citrosuco que começou a produção em Bebedouro (SP) em 2004 e já tinha unidades produtivas no estado de Santa Catarina e nos Estados Unidos. A produção da Citrosuco divide-se em Suco Integral (NFC) e Suco Concentrado e Congelado (FCOJ) $(49 \%)$, farelo de polpa cítrica $(46,5 \%)$, polpa congelada $(1,5 \%)$, óleos e essências (3\%).

A Citrovita é fundada no final dos anos 1990 com fábrica e sede em Catanduva. Em 2009, a fábrica de Catanduva inovou ao converter geradores de gás quente e caldeira em biomassa com capacidade para autossuficiência e exportação de energia elétrica excedente.

A fusão das empresas Citrosuco do Grupo Fischer (unidades em Matão, Limeira, Bebedouro no estado de São Paulo, uma no estado de Santa Catarina e outra na Flórida) e a Citrovita do Grupo Votorantim (unidades em Catanduva, Araras e Matão) foi anunciada em dezembro de 2011. A empresa única resultante mantém o nome de Citrosuco, tem participação acionária de $50 \%$ de cada antigo grupo e assim conseguiu se tornar maior que a Cutrale, a líder nas exportações brasileiras de suco de laranja. A nova empresa tem capacidade instalada de processar acima de $40 \%$ de todo o suco de laranja produzido e exportado pelo Brasil ou produzir $25 \%$ de todo o suco de laranja consumido no mundo consolidando-se como maior produtora mundial de suco de laranja já em 2012. Hoje, a Citrosuco tem fábricas paulistas (Catanduva e Araras) e uma em Lake Wales (Flórida-EUA).

Neste período pós-fusão a indústria do suco de laranja reduz a produção de suco concentrado e aumenta a de refrescos, resultado que em conjunto com a queda na produção do fruto vão minguando os estoques no final do período. Os rendimentos das indústrias sofrem alteração no mesmo período, consequentemente a quantidade de frutos demandada por elas também (Tabela 2).

As relações entre volume da produção e destino para indústria ou consumo direto depende dos estoques disponíveis, preços e rendimento industrial. Aspectos imprescindíveis para compor o circuito de produção da laranja no Brasil.

\section{RENDIMENTO INDUSTRIAL E CONSUMO NOS LARES BRASILEIROS}

A proporção de laranjas destinadas ao consumidor final e a indústria varia segundo fonte e ano safra. Segundo o Departamento de Agricultura dos Estados Unidos (USDA), em torno de $67 \%$ da produção de laranja foi destinada para suco na safra 2012/2013, sendo que na safra seguinte cresceu para $70 \%$. Estimativas do Instituto de Economia Agrícola disponibilizadas pelo departamento econômico do banco Bradesco apontam que na safra 2015/2016 a indústria consumiu $85 \%$ de toda a produção brasileira de laranja. Este estudo também esclarece os percentuais

Estudos Geográficos, Rio Claro, 16(2): 141-155, jul./dez. $2018 \quad$ (ISSN 1678-698X) http://www.periodicos.rc.biblioteca.unesp.br/index.php/estgeo 
fabricados de cada produto industrial, o que pode ser concatenado obedecendo às normas nacionais de classificação, neste caso específico segue a Lista de Produtos e Serviços Industriais utilizados pelo IBGE. Os detalhes constam na Figura 1.

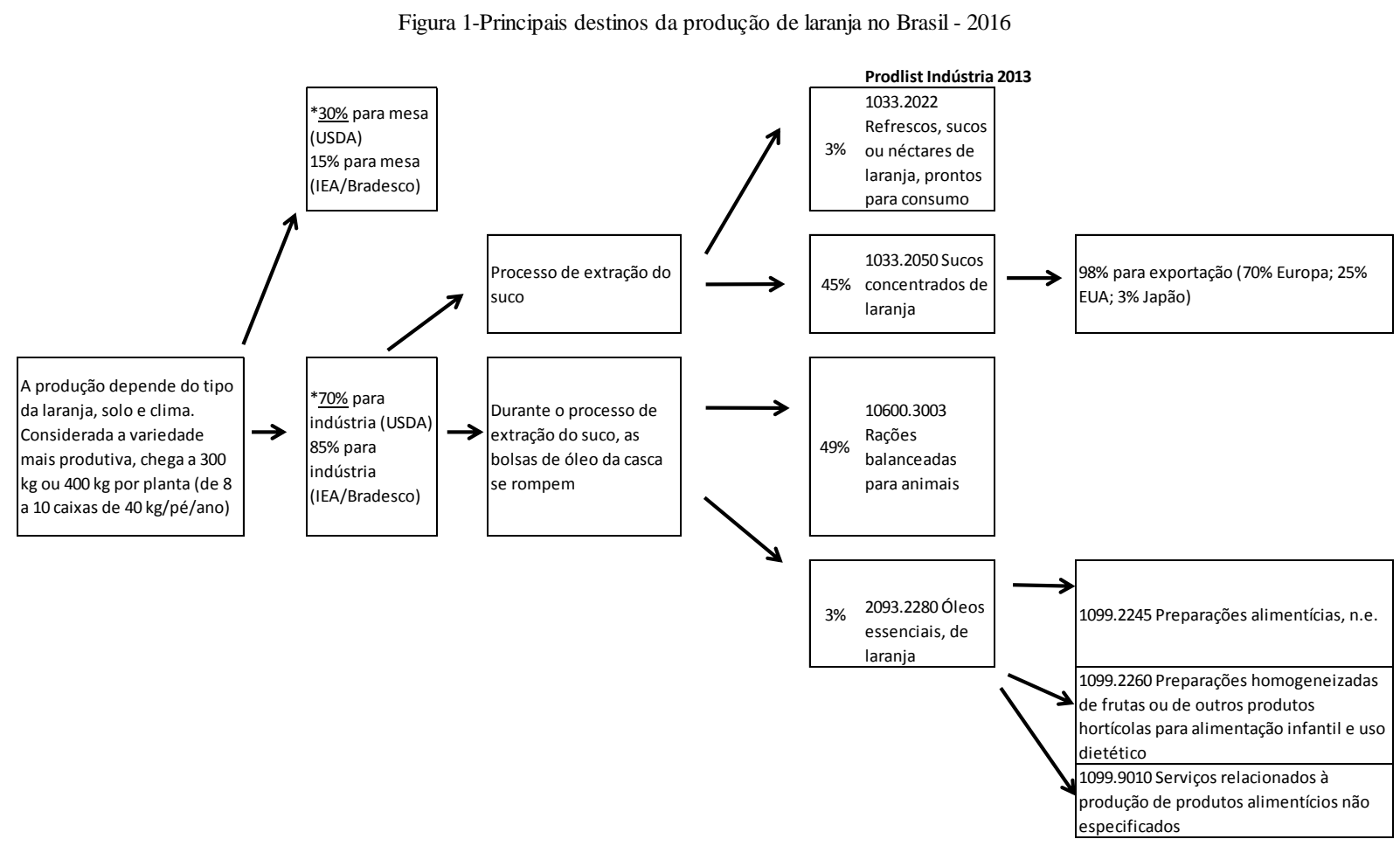

Fonte: Elaboração própria com base em: Instituto de Economia Agrícola-IEA, Secretaria de Comércio Exterior -SECEX, United States Department of Agriculture-USDA

A quantidade de suco extraída do fruto difere segundo teor de açúcar, acidez e outras características, o que muda conforme condições climáticas e de solo de cada safra. Normalmente, o peso médio da laranja é de $0,14 \mathrm{Kg}$ e cabem 286 laranjas por caixa, de tal forma que para fazer um litro de suco são necessárias de 14 a 16 laranjas. Segundo a Citrosuco, as condições climáticas também influenciam este rendimento. No caso de uma seca intensa, parte da produção pode ser acometida pelo fenômeno da cristalização dos açúcares da fruta, resultando em uma diminuição da extração de suco e piora no rendimento industrial. Isso ocorreu na produção brasileira, no segundo semestre de 2015, período com excesso de chuvas, aumento da quantidade de água nas frutas e com isso alterações no rendimento industrial.

Os óleos podem ser utilizados nas indústrias alimentícia, farmacêutica, cosmética e de produtos de limpeza. Segundo os cooperados produtores de óleos essenciais de laranja de Paranavaí-PR é necessária uma tonelada de laranja para produzir apenas 2,5 litros do óleo essencial. Os preços são elevados. Em 2010, pagou-se US\$ 2 mil dólares pela tonelada do produto.

Estudos da Nielsen mostravam que aproximadamente $56 \%$ dos lares brasileiro consumiam sucos prontos em 2009. Para atender a demanda, a Del Valle fez investimentos para ampliar a capacidade das fábricas de sucos e néctares de Americana (SP) e Linhares (ES). Ainda assim, a maior parte da produção de sucos de laranja brasileiro é vendida para países europeus e norte-americanos (Figura 1). O suco de laranja teve queda na série de vendas externas em 2012 logo após o ano que atingiu o auge dos preços para o produto brasileiro no século XXI. De 2012 para 2013, a produção nacional de suco concentrado de laranja diminuiu e o volume das Estudos Geográficos, Rio Claro, 16(2): 141-155, jul./dez. $2018 \quad$ (ISSN 1678 -698X) http://www.periodicos.rc.biblioteca.unesp.br/index.php/estgeo 
exportações sobem um pouco, o que é possível graças à venda dos estoques bem elevadas para o período (Figura 2).

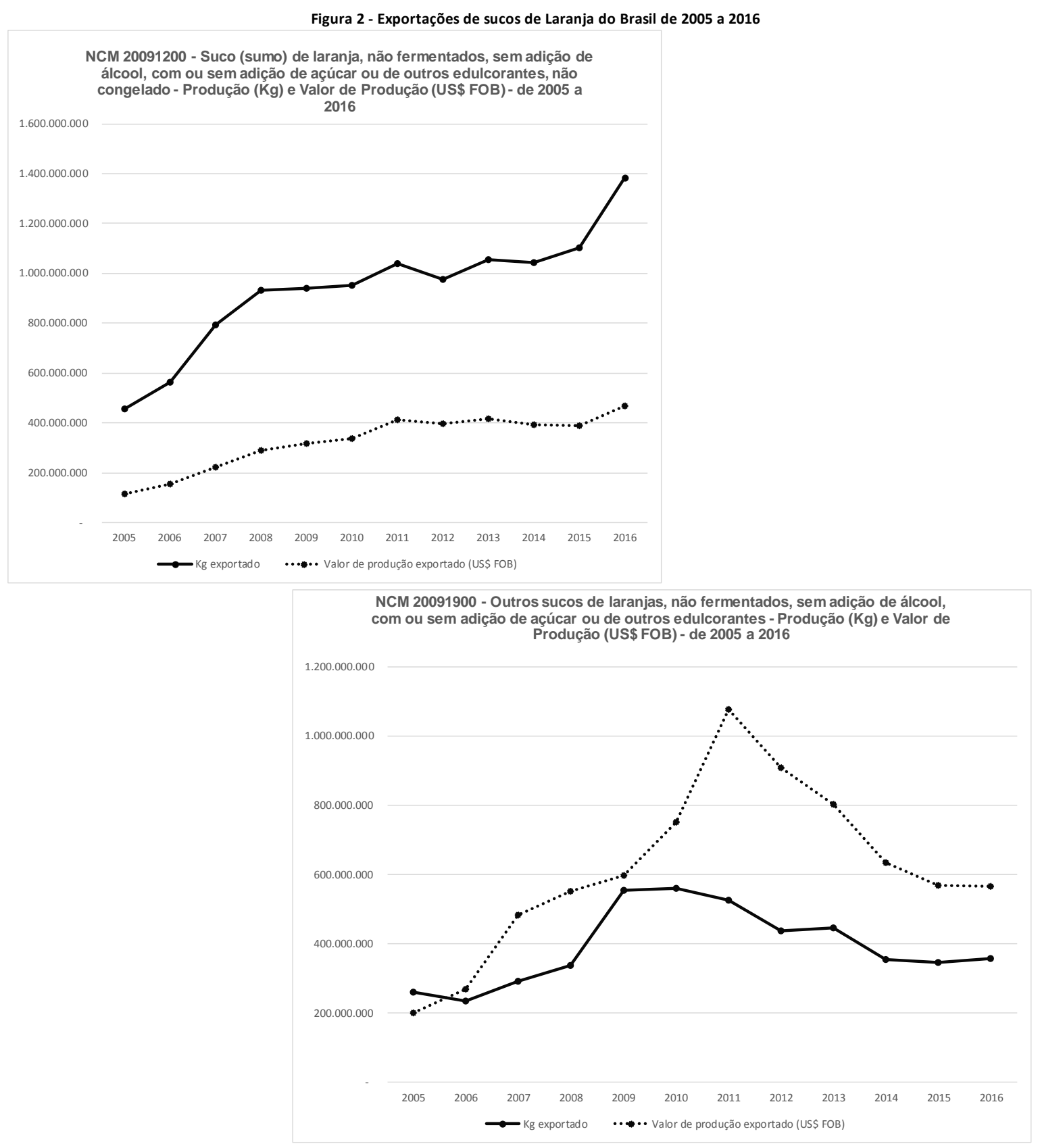

Fonte: MDIC - Ministério da Indústria, Comércio Exterior e Serviços

Grande parte das exportações é proveniente de unidades produtivas paulistas cujos proprietários estão vinculados diretamente a uma indústria específica. O Brasil é um país que tradicionalmente participa pouco do comércio mundial de laranja "in natura". De acordo com os dados de 2011 da Food and Agriculture Organization of the United Nations (FAO) a Espanha destaca-se como o principal exportador mundial de laranjas de mesa seguida de África do Sul e Egito, enquanto os principais compradores são Alemanha, Holanda, França e Rússia. O comércio mundial da laranja fresca representa $45 \%$ de todo o comércio mundial que envolve o circuito de produção da fruta, seguido pela participação do suco simples

$$
\text { Estudos Geográficos, Rio Claro, 16(2): } \quad 141-155, \quad \text { jul./dez. } 2018 \quad \text { (ISSN } \quad \text { 1678-698X) }
$$


$(42 \%)$ e do suco concentrado (13\%). É neste mercado de produtos industrializados, ou seja, nas últimas etapas do circuito da produção da laranja que o Brasil se insere expressivamente no mercado mundial. Enquanto a participação europeia na compra de sucos de laranjas é crescente, a participação das compras norte-americanas vem diminuindo nos últimos anos devido às reduções no consumo interno e mudanças nas revendas internacionais.

\section{CONSIDERAÇÕES FINAIS}

As concentrações da área de cultivo da laranja no território paulista e da localização das principais indústrias produtoras de sucos no mesmo estado caracterizam o circuito de produção da laranja no Brasil. A intenção principal do plantio é gerar produto destinado à exportação. O trabalho mostra que o fato não é recente, os fluxos de comercialização e cooperação do circuito de produção da laranja nascem com o desenvolvimento deste cultivo no país, contudo, intensificamse suas relações com o avanço do meio técnico-científico-organizacional. São capazes de reorganizar o território urbano e rural e extrapolar o limite do território nacional. Os pequenos produtores rurais dão espaço aos médios produtores e cresce a concentração dos grupos industriais, principalmente após a fusão de Citrosuco e Citrovita superando o domínio da gigante Cutrale. Os círculos de cooperação mostram sua força na participação do país no mercado internacional de suco de laranja, tanto na formação dos preços, quanto na comercialização.

No mercado externo, o país está entre os líderes de venda e grande influenciador na formação dos preços do suco de laranja, inclusive há empresas de capital nacional que têm fazendas produtoras de laranja na Flórida. Como bem salienta Sampaio (2003), historicamente a produção e a produtividade dos alimentos destinados ao mercado interno se modernizam menos que os demais produtos industriais exportados. No caso da laranja no Brasil, a consolidação de novas técnicas produtivas foi ocorrendo graças à modernização da estrutura interna que foi sendo desenvolvida para atender as crescentes exigências do mercado internacional. Em nome do atendimento a essa demanda, perduraram as inovações físico-químicas, mecânicas e biológicas já identificadas como fundamentais para os primórdios do progresso técnico na agricultura segundo José Graziano da Silva (1981).

Entretanto, ainda é uma atividade bastante dependente das condições climáticas e da ausência de pragas para determinação dos resultados do plantio que consequentemente acabam por influenciar muito a formação dos preços dos sucos no mercado internacional e na oscilação dos estoques. Por conta disso, os produtores têm buscado avanços tecnológicos para desenvolver frutos mais resistentes e com maior rentabilidade para a indústria. Frutos de boa qualidade acarretam maior rentabilidade para produtores industriais, porém há limites para 0 processamento dos frutos que pode ser reduzido drasticamente devido à indisponibilidade de: instalações e mão de obra para produção e/ou local adequado para estoque do produto acabado. A quantidade de estoques de suco de laranja e consequentemente de seus preços também acabam por influenciar as decisões de produção das indústrias e, portanto, a demanda pelo fruto.

O trabalho mostrou que esta combinação de fatores, controlados em grande parte por poucos grandes grupos industriais em parceria com produtores que estão se tornando cada vez maiores, é que dá dinâmica ao movimento do circuito de

Estudos Geográficos, Rio $\quad$ Claro, 16(2): 141-155, jul./dez. $2018 \quad$ (ISSN 1678 -698X) http://www.periodicos.rc.biblioteca.unesp.br/index.php/estgeo 
produção da laranja no Brasil. Parte do território paulista é fundamental neste processo, tanto para produção do fruto, quanto para processamento industrial dos sucos. Mostra-se, com isso, crescente concentração: territorial, de capital e de mão de obra neste circuito produtivo.

\section{REFERÊNCIAS}

ASSOCIAÇÃO BRASILEIRA DE CITRICULTORES - ASSOCITRUS. Disponível em: http://www.canalrural.com.br/noticias/agricultura/preco-pago-produtor-pela-caixalaranja-cai-2011-3809. Acesso em: 25 ago. 2016.

ASSOCIAÇÃO NACIONAL DOS EXPORTADORES DE SUCOS CÍTRICOS CitrusBR. $\quad$ Disponível em: http://revistagloborural.globo.com/Revista/Common/0,,EMI328046-18282-14,00-

SAFRA+DE+R+BILHOES.html. Acesso em: 04 nov. 2016.

ASSOCIAÇÃO NACIONAL DOS EXPORTADORES DE SUCOS CÍTRICOS CitrusBR. Disponível em: http://www.citrusbr.com/estoques/. Acesso em: 09 nov. 2016.

ARROYO, Mónica. A economia invisível dos pequenos. Le Monde Diplomatique Brasil. 4 de outubro de 2008. Disponível em: <http://diplomatique.org.br/a-economiainvisivel-dos-pequenos/>. Acesso em: 08 mar. 2016.

BOECHAT, Cássio Arruda. A questão agrária e a crise da citricultura brasileira. Programa de Pós-Graduação em Ciências Sociais - UFJF v. 10 n. 2 jul/dez. 2015. Disponível em: https://teoriaecultura.ufjf. Acessado em: 10 out. 2016.

CENTRO DE ESTUDOS AVANÇADOS EM ECONOMIA APLICADA - CEPEA/Esalq. Disponível em: <http://revistagloborural.globo.com/Revista/Common/0,,ERT30772418532,00.html>. Acesso em: 25 jun. 2016.

CITROVITA. Disponível em: http://economia.estadao.com.br. Acesso em: 19 fev. 2016.

CUTRALE. Disponível em: http://www.cutrale.com.br. Acesso em: 05 jun. 2016.

ELIAS, Denise. Região de Ribeirão Preto: o Brasil agrícola moderno. Outubro, 1996. Disponível em: <http://www.revistas.usp.br/geousp/article/view/123228>. Acesso em: 08 mai. 2015.

FOOD AND AGRICULTURE ORGANIZATION OF THE UNITED NATIONS - FAO. Disponível em: www.agricultura.gov.br. Acesso em: 28 nov. 2016.

FUNDO DE DEFESA DA CITRICULTURA - FUNDECITRUS. Disponível em: http://economia.uol.com.br. Acesso em: 22 out. 2016.

GRUPO FISHER. Disponível em: http://www.citrosuco.com.br. Acesso em: 02 mai. 2016.

Estudos Geográficos, Rio Claro, 16(2): 141-155, jul./dez. $2018 \quad$ (ISSN 1678-698X) http://www.periodicos.rc.biblioteca.unesp.br/index.php/estgeo 
INSTITUTO BRASILEIRO DE GEOGRAFIA E ESTATÍSTICA - IBGE. Censo Agropecuário 2006. Disponível em: < http://www.ibge.gov.br>. Acesso em: 12 mar. de 2015.

INSTITUTO BRASILEIRO DE GEOGRAFIA E ESTATÍSTICA - IBGE. Pesquisa Agrícola Municipal 2001 a 2015. Disponível em: < http://www.ibge.gov.br>. Acesso em: 06 jan. de 2016.

INSTITUTO BRASILEIRO DE GEOGRAFIA E ESTATÍSTICA - IBGE. Pesquisa Industrial Anual 2005 a 2014. Disponível em: < http://www.ibge.gov.br>. Acesso em: 01 mai. de 2016.

INSTITUTO DE ECONOMIA AGRÍCOLA - IEA. Disponível em: https://www.economiaemdia.com.br/EconomiaEmDia/pdf/infset_suco_de_laranja.pdf > Acesso em: 22 mai. 2016.

JORNAL VALOR ECONÔMICO. Demanda mundial por suco de laranja volta ao patamar dos anos 1980.10 Disponível http://www.valor.com.br/agro/4687889/demanda-mundial-por-suco-de-laranja-voltaao-patamar-dos-anos-1980\#. Acesso em: 24 fev. 2016.

MACIEL, Lidiane Maria. Brasil de Fato: A invisibilidade gerada pela citricultura. 18 de dezembro de 2012.2 Disponível em: https://www.brasildefato.com.br/node/11445/. Acesso em: 05 set. 2016.

NEVES, Marcos Fava. O retrato da citricultura brasileira. Disponível em: $<$ http://www.citrusbr.com/download/biblioteca/Apresentacao_Marcos_Fava_evento_v alor.pdf> Acesso em: 13 set. 2016.

INSTITUTO OBSERVATÓRIO SOCIAL - OBS. Cultivo de laranja e produção de suco: indicativos de déficit de trabalho decente na Citrosuco S/A Agroindústria Sucocítrico Cutrale Ltda. Louis Dreyfus Commodities Agroindustrial S/A, maio de 2013. Disponível em: www.reformaagrariaemdados.org.br. Acesso em: 01 fev. 2018.

SAMPAIO, Fernando dos Santos. Made in Brazil: dinâmica sócio-espacial da indústria citrícola paulista. 2003. Tese (Doutorado). Programa de Pós Graduação em Geografia Humana. São Paulo. 2003.

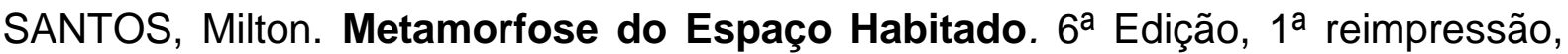
São Paulo/SP: Editora da Universidade de São Paulo, 2008.

SANTOS, Milton \& SILVEIRA, María Laura. O Brasil: território e sociedade no início do século XXI. 9a Edição, Rio de Janeiro/RJ; Record, 2006.

SECRETARIA DE COMÉRCIO EXTERIOR - SECEX. Disponível em: https://www.economiaemdia.com.br/EconomiaEmDia/pdf/infset_suco_de_laranja.pdf > Acesso em: 25 mai. 2016.

SILVA, José Graziano. O Que é questão agrária? Editora Brasiliense. 2ª Edição, 1981.

Estudos Geográficos, Rio Claro, 16(2): 141-155, jul./dez. $2018 \quad$ (ISSN $\quad$ 1678-698X) http://www.periodicos.rc.biblioteca.unesp.br/index.php/estgeo 
SINDICATO NACIONAL DA CERVEJA - SINDICERV. Disponível em: http://www1.folha.uol.com.br/mercado/823139-brasil-vira-prioridade-para-empresasde-bebidas-setor-pode-investir-ate-r-4-bilhoes.shtml. Acesso em 01 de março de 2017.

UNITED STATES DEPARTMENT OF AGRICULTURE - USDA. Disponível em: http://revistagloborural.globo.com/Noticias/Agricultura/Laranja/noticia/2014/01/produc ao-mundial-de-laranjas-deve-aumentar-5-em-20132014-preve-usda.html> Acesso em: 07 mar. 2016.

Artigo submetido em: 18/05/2018 Aceito para publicação em: 25/10/2018

Publicado em: 14/12/2018 